\title{
Meningkatkan Kemampuan Kognitif Mengurutkan Bilangan 1-10 Melalui Media Pohon Hitung Anak Kelompok B Di TK Baptis Setia Bakti Kota Kediri
}

\author{
Erlina \\ TK. Baptis Setia Bakti \\ Kota Kediri \\ erlinatkbaptis.kdr@gmail.com
}

\begin{abstract}
Abstrak
Penelitian ini dilatarbelakangi hasil pengamatan dan pengalaman peneliti bahwa kemampuan kognitif khususnya kemampuan berhitung dalam membilang lambang bilangan dan mengurutkan bilangan 1-10 kurang diminati anak karena faktor media yang kurang mendukung, selain itu guru belum menerapkan pembelajaran yang menyenangkan sehingga anak mudah bosan. Media merupakan sarana untuk membangkitkan motivasi belajar sehingga sangat diperlukan untuk pengembangan kemampuan berhitung secara optimal. Berdasarkan latar belakang masalah tersebut dirumuskan permasalahan yang diteliti yaitu: Apakah penggunaan media pohon hitung dapat meningkatkan kemampuan kognitif anak terutama dalam membilang dan mengurutkan lambang bilangan 1-10. Penelitian ini menggunakan pendekatan Penelitian Tindakan Kelas (PTK) kolaboratif dengan sampel anak didik kelompok B TK Baptis Setia Bakti Kota Kediri sejumlah 20 anak. Penelitian ini dilakukan dalam dua siklus, menggunakan penilaian, lembar observasi siswa dan lembar observasi guru. Kesimpulan hasil penelitian ini adalah: Melalui pembelajaran menggunakan media pohon hitung terbukti berhasil dan dapat meningkatkan kemampuan kognitif membilang dan mengurutkan lambang bilangan 1-10 anak kelompok B.

Implikasi praktis hasil penelitian ini adalah tujuan pendidikan pada satuan pendidikan PAUD lebih diutamakan pada peningkatan kemampuan dasar. Untuk membentuk kemampuan dasar yang kuat diperlukan beberapa hal diantaranya adalah penggunaan Alat Peraga Edukatif yang menarik minat anak. Media pohon hitung terbukti dapat memenuhi tujuan tersebut, untuk itu dinarapkan guru PAUD dapat menggunakannya dalam pembelajaran untuk meningkatkan penguasaan kemampuan dasar.
\end{abstract}

Kata kunci: membilang, mengurutkan bilangan, pohon hitung, anak TK.

\section{PENDAHULUAN}

Salah satu bentuk pengembangan yang ada dalam pembelajaran di TK adalah pengembangan kemampuan kognitif. Ada beberapa kegiatan yang bisa diberikan dalam pembelajaran TK yang sesuai dengan pengembangan kemampuan kognitif seperti membilang dan mengurutkan angka 1-10, menunjuk lambang bilangan 1-10, meniru lambang bilangan 1-10 penjumlahan dan pengurangan dengan benda 1-10, mengenal konsep waktu dan masih lagi. Berhitung merupakan bagian dari pengembangan kemampuan kognitif. Pembelajaran berhitung di TK biasanya diberikan secara integrasi pada program pengembangan yang lain.

$$
\text { Berdasarkan pengamatan awal }
$$


terhadap kegiatan pengembangan kognitif di TK Baptis Setia Bakti diidentifikasi adanya kurangnya kemampuan anak didik memahami bilangan angka 1-10. Kondisi kurang aktifhya anak didik dalam pembelajaran pengembangan kognitif berpengaruh pada pengembangan dan hasil belajar anak didik. Hal ini disebabkan karena strategi pembelajaran yang digunakan kurang menarik minat anak, karena guru hanya menggunakan media pembelajaran berupa tulisan di papan tulis, sehingga dalam proses pembelajaran anak merasa bosan. Kurangnya guru dalam memberikan stimulus-stimulus dengan media pembelajaran yang konkret atau kurang nyata tentang bilangan juga menjadi faktor kurang berkembangnya kemampuan kognitif anak terutama dalam mengenal dan memahami bilangan 1-10.

Oleh karena itu, melihat kondisi yang seperti ini peneliti ingin mencoba mengembangkan kemampuan kognitif anak melalui media pohon hitung agar kemampuan kognitif anak dalam berhitung bilangan 1-10 benarbenar matang dan lebih memahami dan menguasainya. Sesuai dengaa permasalahan tersebut diatas, maka judul penelitian ini adalah "Meninkatkan Kemampuan Kognitif Mengurutkan Bilangan 1-10 Melalui Media Pohon Hitung Di Kelompok B TK Baptis Setia Bakti Kota Kediri”.

\section{KAJIAN PUSTAKA}

\section{Kemampuan Kognitif}

Menurut Colvia dalam (Sujiono.Y, 2006) kognitif adalah kemampuan untuk menyesuaikan diri dengan lingkungan. Sedangkan Supeno, (2006) menyatakan bahwa kognitif adalah suatu proses berpikir, yaitu kemampuan individu untuk menghubungkan, menilai dan mempertimbangkan suatu kejadian atau peristiwa.

Piaget dalam Fridani dkk, (1980) menyatakan tahapan perkembangan kognitif anak usia dini dibagi menjadi tiga tahapan sebagai berikut :

1. Tahap Sensorimotor (0-18 bulan)

2. Tahap Pra Operasional (18 buian6/7 tahun)

3. Tahap Operasionai Konkret (8-12 tahun)

Menurut Depdiknas (2000:8) mengemukakan prinsip-prinsip dalam menerapkan permainan berhitug di Taman kanak-kanak yaitu, permainan berhitung diberikan secara bertahap, diawali dengan menghitung benda-berda atau pengalaman peristjwa konkrit yang dialami melalui tingkat kesukarannya.

Depdiknas

(2000:7)

mengemukakan bahwa berhitung di Taman Kamk-Kanak seyogyanya dilakukan melalui tiga tahapan penguasaan di jatur matematika yaitu : 1 . penguasaan konsep 2. Masa transisi 3 . Penguasaan lambang

\section{Media Pohon Hitung}

Media berasal dari bahasa latin "medium" yang artinya perantara yaitu perantara sumber pesan (a source) dengan penerima pesan (a receiver). Menurut Scharamm \{1977) dalam Badru Zaman dkk, (2005) media adalah : Teknologi pembawa pesan yang dapat dimanfaatkan untuk keperluan pembelajaran. Menurut Heinick, Molenda, dan Rassell (1993) dalam Badru Zaman dkk, (2005) media merupakan saluran komunikasi yaitu perantara sumber pasan dengan menerima pesan.

Media pohon hitung merupakan 
mainan edukasi untuk melatih berhitung anak-anak melalui media permainan edukatif dan media yang tidak asing lagi di pembelajaran.

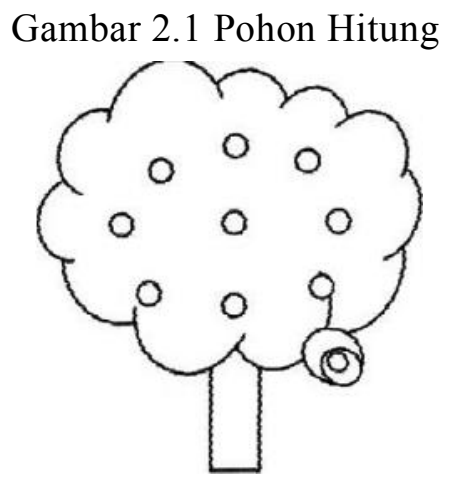

Keterangan:

1. Pohon hitung harus bisa berdiri.

2. Diberi alat untuk menggantung benda.

3. Bahan dari kayu, triplek, karton.

Manfaat media pohon hitung yaitu Berlatih berhitung, mengenal angka. pengenalan aneka benda, melatih kreativitas, motorik halus dan emosi.

Kemampuan kognitif merupakan suatu proses berpikir berupa kemampuan untuk menghubungkan, menilai dan mempertimbangkan sesuatu. Kurangnya guru dalam memberikan stimulusstimulus dengan media pembelajaran yang konkret atau nyata tentang bilangan juga menjadi faktor kurang berkembangnya kemampuan kognitif anak terutama dalam memahami dan mengurutkan bilangan 1-10. Hal ini dapat dilihat dari hasil pembelajaran anak didik setiap mengerjakan tugas mengurutkan bilangan, suasana kelas ramai, anak jalanjalan sendiri dan tidak memperhatikan guru.

Melihat kondisi yang semacam ini peneliti mencoba mengembangkan kemampuan kognitif memahami dan mengurutkan bilangan 1-10 media pohon hitung agar kemampuan kognitif anak selalu memahami bilangan seta sebagai persiapan memasuki sekolah yang lebih lanjut lebih matang.

\section{METODE PENELITIAN}

Subyek dalam penelitian ini adalah anak kelompok B TK Baptis Setia Bakti Kecamatan Pesantren Kota Kediri semester I Tahun Pelajaran 2016-2017 dengan jumlah anak didik sebanyak 20 anak.

Penelitian tindakan kelas ini menggunakan desain model Kemmis dan Taggart yang terdiri (1) Perencanaan (2) Tindakan (3) Pengamatan (4) Refleksi.

Instrumen pengumpulan data yang digunakan dalam penelitian tindakan kelas ini adalah :

\begin{tabular}{|c|c|c|c|c|c|}
\hline \multirow[t]{2}{*}{ No } & \multirow{2}{*}{\begin{tabular}{|c|} 
\\
Subjek \\
Peneliti \\
an
\end{tabular}} & \multicolumn{3}{|c|}{\begin{tabular}{|c|} 
Nilai \\
Perkemban \\
gan \\
Anak \\
Didik \\
\end{tabular}} & \multirow[t]{2}{*}{ Keterangan } \\
\hline & & \begin{tabular}{l|l|}
$*$ & $*$ \\
& $*$
\end{tabular} & $\begin{array}{c}* * \\
* \\
\end{array}$ & $\begin{array}{l}* \\
* \\
* \\
*\end{array}$ & \\
\hline 1 & & & & & $*=$ belum mampu \\
\hline 2 & & & & & $\begin{array}{l}* *=\text { Mampu } \\
\text { dengan Bantuan } \\
\text { guru }\end{array}$ \\
\hline 3 & & & & & $\begin{array}{l}* * *=\text { Mampu } \\
\text { tanpa Bantuan } \\
\text { guru }\end{array}$ \\
\hline 4 & & & & & $\begin{array}{l}* * * *=\text { Mampu } \\
\text { tanpa Bantuan } \\
\text { guru Dan } \\
\text { memuaskan }\end{array}$ \\
\hline \multirow[t]{2}{*}{ Dst } & & & & & \\
\hline & Jumlah & & & & \\
\hline
\end{tabular}

Metode analisis data pada penelitian ini bersama teman sejawat mengolah data yang terkumpul dan 
menentukan kriteria penilaian keberhasilan anak didik dalam meningkatkan kemampuan kognitif dengan menggunakan media pohon hitung.

Penelitian ini dianalisis dengan menggunakan rumus:

$$
P=\frac{f}{n} \times 100 \%
$$

Keterangan:

P : hasil jawaban dalam \%

$\mathrm{f}$ : Nilai yang diperoleh

$\mathrm{n}$ : Jumlah item pengamatan dengan nilai tertinggi

\section{HASIL DAN PEMBAHASAN}

Penelitian ini dilakukan di kelompok B TK Baptis Setia Bakti Kota Kediri Tahun Pelajaran 2016-2017 dengan jumlah anak didik sebanyak 20 anak.

\section{Deskripsi Temuan Penelitian Pelaksanaan Siklus I}

Siklus I dilaksanakan pada tanggal

27 Agustus 2016 dengan hasil penelitian sebagai berikut:

Lembar Hasil Observasi Anak Didik dalam pembelajaran Mengurutkan

Bilangan 1-10 Melalui Media Pohon Hitung Siklus I

\begin{tabular}{|c|c|c|c|c|c|}
\hline \multirow[t]{2}{*}{ No } & \multirow{2}{*}{$\begin{array}{l}\text { Subjek } \\
\text { Peneliti } \\
\text { an }\end{array}$} & \multicolumn{3}{|c|}{$\begin{array}{c}\text { Nilai } \\
\text { Perkemban } \\
\text { gan } \\
\text { Anak } \\
\text { Didik } \\
\end{array}$} & \multirow[t]{2}{*}{ Keterangan } \\
\hline & & \begin{tabular}{|l|l}
$*$ & $*$ \\
& $*$
\end{tabular} & $\begin{array}{c}* * \\
*\end{array}$ & $\begin{array}{l}* \\
* \\
* \\
*\end{array}$ & \\
\hline 1. & Ad & & $\sqrt{ }$ & & \\
\hline 2. & $\mathrm{Am}$ & $\sqrt{ }$ & & & $*=$ belum mampu \\
\hline 3. & Add & $\sqrt{ }$ & & & \\
\hline 4. & Brn & & $\sqrt{1}$ & & $\begin{array}{l}* *=\text { Mampu } \\
\text { dengan Bantuan } \\
\text { guru }\end{array}$ \\
\hline 5. & Crll & & & $\sqrt{ }$ & \\
\hline
\end{tabular}

\begin{tabular}{|c|l|l|c|c|c|l|}
\hline 6. & Dhe & & & $\sqrt{ }$ & & \\
\hline 7. & Ely & & $\sqrt{ }$ & & & $\begin{array}{l}* * *=\text { Mampu } \\
\text { tanpa Bantuan } \\
\text { guru }\end{array}$ \\
\hline 8. & Erd & & & & $\sqrt{ }$ & \\
\hline 9. & Gnn & & & & $\sqrt{ }$ & \\
\hline 10. & Hki & & & $\sqrt{ }$ & & $\begin{array}{l}* * * *=\text { Mampu } \\
\text { tanpa Bantuan } \\
\text { guru Dan } \\
\text { memuaskan }\end{array}$ \\
\hline 11. & Jea & & $\sqrt{ }$ & & & \\
\hline 12. & Ivn & $\sqrt{ }$ & & & & \\
\hline 13. & Kia & & $\sqrt{ }$ & & & \\
\hline 14. & LI & & & & $\sqrt{ }$ & \\
\hline 15. & Mss & & & $\sqrt{ }$ & & \\
\hline 16. & Mri & $\sqrt{ }$ & & & & \\
\hline 17. & Mrg & $\sqrt{ }$ & & & & \\
\hline 18. & Mic & $\sqrt{ }$ & & & & \\
\hline 19. & Ni & $\sqrt{ }$ & & & & \\
\hline 20. & Rg & & $\sqrt{ }$ & & & \\
\hline & Jumlah & 1 & 9 & 6 & 4 & \\
\hline
\end{tabular}

Berdasarkan hasil penelitian yaag dilakukan pada siklus I, ketuntasan kemampuan anak didik mencapai $50 \%$ karena 10 anak didik bdum mampu sehingga perlu dilakukan sikius berikutnya.

\section{Pelaksanaan Siklus II}

Siklus II dilaksanakan pada tanggal 3 September 2016 dengan hasil sebagai berikut:

Lembar Hasil Observasi Anak Didik dalam Pembelajaran Mengurutkan Bilangan 1-10 Melalui Media Pohon Hitung Siklus II

\begin{tabular}{|c|c|c|c|c|c|}
\hline \multirow{2}{*}{ No } & \multirow{2}{*}{$\begin{array}{c}\text { Subjek } \\
\text { Penelitian }\end{array}$} & \multicolumn{3}{|c|}{\begin{tabular}{|c|} 
Nilai \\
Perkemban \\
gan \\
Anak \\
Didik \\
\end{tabular}} & \multirow{2}{*}{ Keterangan } \\
\hline & & \begin{tabular}{|l|l}
$*$ & $*$ \\
& $*$
\end{tabular} & $\begin{array}{l}* * \\
*\end{array}$ & $\begin{array}{l}* \\
* \\
* \\
*\end{array}$ & \\
\hline 1. & $\mathrm{Ad}$ & & & $\sqrt{ }$ & \\
\hline 2. & $\mathrm{Am}$ & $\sqrt{ }$ & & & $*=$ belum mampu \\
\hline
\end{tabular}

http://ojs.unpkediri.ac.id 


\begin{tabular}{|c|c|c|c|c|c|c|}
\hline 3. & Add & & & $\sqrt{ }$ & & \\
\hline 4. & Brn & & & & $\sqrt{ }$ & ** = Mampu dengan \\
\hline 5. & Crll & & & & $\sqrt{ }$ & Bantuan guru \\
\hline 6. & Dhe & & & & $\sqrt{ }$ & \\
\hline 7. & Ely & & & $\sqrt{ }$ & & *** = Mampu tanpa \\
\hline 8. & Erd & & & & $\sqrt{ }$ & Bantuan guru \\
\hline 9. & Gnn & & & & $\sqrt{ }$ & \\
\hline 10 . & Hki & & & & $\sqrt{ }$ & $\begin{array}{l}* * * *=\text { Mampu } \\
\text { tanpa Bantuan guru }\end{array}$ \\
\hline 11. & Jea & & & $\sqrt{ }$ & & Dan memuaskan \\
\hline 12. & Ivn & & $\sqrt{1}$ & & & \\
\hline 13. & Kia & & & $\sqrt{ }$ & & \\
\hline 14. & LI & & & & $\sqrt{ }$ & \\
\hline 15. & Mss & & & & $\sqrt{ }$ & \\
\hline 16. & Mri & & & $\sqrt{ }$ & & \\
\hline 17. & Mrg & & & $\sqrt{ }$ & & \\
\hline 18. & Mic & & & $\sqrt{ }$ & & \\
\hline 19. & $\mathrm{Ni}$ & & & $\sqrt{ }$ & & \\
\hline 20. & $\mathrm{Rg}$ & & & $\sqrt{ }$ & & \\
\hline & Jumlah & $0 \mid 2$ & 2 & 9 & 9 & \\
\hline
\end{tabular}

Berdasarkan basil penelitian yang dilakukan pada siklus II, kemampuan anak dalam memahami mengurutkan lambang bilangan 1-10 telah meningkat dengan baik sehingga media pohon hitung dapat dijadikan sebuah alternative cara untuk mengembangkan kemampuan anak dalam memahami mengurutkan lambang bilangan 1-10.

Berdasarkan hasil penelitian dari siklus 1 dan II kemampuan anak dalam mengurutkan lambang bilangan 1-10 telah berkembang sesuai harapan. Hal tersebut tampak dari tabel sebagai berikut:

Rekapitulasi Hasil Observasi Anak dalam Mengurutkan Bilangan 1-10

Dengan Menggunakan Media Pohon Hitung Siklus I-II

\begin{tabular}{|c|c|c|c|c|c|c|}
\hline \multirow{4}{*}{ No } & \multirow{3}{*}{ Siklus } & \multicolumn{3}{|c|}{ Nilai } & \\
& & \multicolumn{4}{|c|}{ an } & Perkembang \\
Anak Didik & Ketuntas \\
& & $*$ & $*$ & $*$ & $*$ & Belajar \\
\cline { 3 - 5 } & & 2 & 2 & 3 & 4 & \\
\hline
\end{tabular}

\begin{tabular}{|l|l|l|l|l|l|l|}
\hline 1. & I & 1 & 9 & 6 & 4 & $66,25 \%$ \\
\hline 2. & II & 0 & 2 & 9 & 9 & $83,75 \%$ \\
\hline
\end{tabular}

Dari hasil penelitian di atas, dapat disimpulkan bahwa melalui penggunaan media pohon hitung dapat meningkatkan kemampuan kognitif anak pada anak didik kelompok B TK Baptis Setia Bakti Kota Kediri, sehingga hipotesis tindakas dalam penelitian ini, diterima.

Kendala yang dijumpai peneliti selama melaksanakan penilaian adalah respon anak yang masih kurang tidak memperhatikan apa yang disampaikan guru, kemampuan guru dalam menyampaikan materi tidak menggunakan metode yang bervariasi, pengelolaan kelas yang kurang kreatif dan inovatif serta terbatasnya media pembelajaran yang dimiliki oleh sekolah.

\section{SIMPULAN DAN SARAN Simpulan}

Berdasarkan hasil penelitian tindakan kelas yang dilakukan dapat disimpulkan bahwa pembelajaran dengan menggunakan media pohon hitung terbukti berhasil dan mampu meningkatkan kemampuan kognitif anak didik dalam mengurutkan bilangan 1-10 sehingga hipotesis dalam penelitian ini dapat diterima.

\section{Saran}

Bagi Guru TK, Hasil prestasi belajar anak didik yang telah dicapai dalam penelitian ini hendaknya tetap diperhatikan bahkan ditingkatkan. Bagi anak, Anak belajar membilang dan mengurutkan lambang bilangan dengan teknik yang beragam dan media yang cukup bervariasi, untuk meningkatkan kemampuan kognitif anak Bagi Lembaga Pendidikan, Sekolah dapat memfasilitasi pembelajaran, menyelenggarakan pelatihan 
dan ketrampilan bagi para pendidik serta mensosialisasikan media pembelajaran yang murah, aman dan tahan lama.

\section{DAFTAR PUSTAKA}

Aisyah, S.,dkk. 2008. Perkembangan dan Konsep Dasar Pendidikan Anak Usia Dini. Jakarta : Universitas Terbuka.

Arikunto, Suharmini, (2005), Dasar Dasar Evaluasi Pendidikan, Jakarta; Bumi Aksara.

Depdiknas Tahun 2005 Kurikulum 2004. Standart Kompetensi Taman Kanak-Kanak dan RA. Jakarta : Dirjen Pendidikan Dasar dan Menengah.

Depdiknas. 2007. Pedoman Pembelajaran Permainan Berhitung Permulaan di Taman Kanak-Kanak. Jakarta.

Direktorat Pembinaan TK dan SD, 2010, Pedoman Pembelajaran Bidang
Pengembangan Kognitif TK Bermain Bilangan. Jakarta : Kementrian Pendidikan Nasional Direktorat Jenderal Manajemen Pendidikan Dasar dan Menengah.

Fridani, Lara dkk, 2010. Evaluasi Perkembangan Anak Usia Dini, Jakarta : Universitas Terbuka.

Sujiono,Yuliani, 2006, Metode Pengembangan Kognitif, Jakarta : Universitas Terbuka.

Wardhani, IGAK dan Wihardi, K 2002, Penelitan Tindakan Kelas, Jakarta : Universitas Terbuka.

Waseso, Iksan dkk, 2007. Evaluasi pembelajaran TK. Jakarta : Universitas Terbuka.

Zaman, Badru dkk, 2007. Media dan Sumber Belajar TK, Jakarta : Universitas Terbuka. 